\title{
Poor Dental Health in British Army Infantry Recruits Reduces their Quality of Life: A cross-sectional survey and retrospective analysis of health records
}

\section{Structured abstract}

Introduction: Oral Health Related Quality of Life (OHRQoL) is a determinant of an individual's wellbeing and can be affected by dental disease. For military recruits, adverse OHRQoL may result in poor performance, and has safety implications. The aim of this study was to determine the incidence of dental extractions and dental health of a sample of new infantry recruits.

Method: Electronic healthcare recordings of tooth extraction incidence was compared to recruits from the general military population. Clinical dental examinations and patient questionnaires were used to determine the prevalence and impact of caries using the PUFA (Pulp exposure, Ulceration, Fistula, Caries) criteria. The association between caries and PUFA lesions with self-reported oral health behaviors and beliefs was explored.

Results: The incidence of tooth extraction was 2.4 times higher in new Army Infantry recruits than recruits in the general UK military population. 211 recruits were assessed, with a $100 \%$ response rate. $135 / 211$ (64\%) had caries, and $37 / 21117.5 \%$ had a PUFA lesion at the time of inspection. Sleep loss was significantly more likely in those with PUFA lesions than those without (OR 5.62, p <0.0001).

Conclusions: Those military Infantry recruits with caries and PUFA lesions had worse OHRQoL than those that did not. This was evidenced by poorer sleeping patterns and an inability to perform tasks at work. Treatment of dental disease through extractions was higher in Army Infantry recruits and will likely reduce the number of days taken off sick, but its effect on overall OHRQoL cannot yet be substantiated. 


\section{Original Research}

\section{Key messages}

1. Non-regular dental attenders were more than 4 times more likely than regular attenders to have an 'urgent' dental condition.

2. Tooth extraction rates were found to be 2.4 times higher in Infantry recruits than recruits in the general UK military population.

3. Sleep loss was significantly more likely in those with PUFA (Pulp exposure, Ulceration, Fistula, Caries) lesions than those without.

4. Focused resources are required to reduce dental morbidity and associated sleep disturbance in this group.

\section{Introduction}

Poor dental health remains a common, and generally preventable, source of morbidity for UK military personnel deploying on operations abroad [1]. Access to dental treatment when deployed is challenging, and where disease cannot be managed on operations, aeromedical evacuation is required, with resultant financial and resource implications $[2,3,4]$. In conflict zones this may place everyone in the evacuation chain at risk [1]. For UK military personnel serving in Afghanistan between 2011-2012, median waiting times for emergency dental care ranged from 2-7 days depending if the patient was co-located with a dental centre. Delays to receiving emergency dental care can have severe consequences, not only increasing risk of medical complications, but also resulting in prolonged pain and difficulty in eating [1].

Oral Health Related Quality of Life (OHRQoL) is a determinant of an individual's wellbeing and relates to oral and dental health $[5,6]$. In the military, poor OHRQoL has additional consequences for military personnel over their civilian counterparts, reflecting their unique roles and responsibilities. A military person lacking sleep for example due to dental pain may not only have poor performance in physical and mental tasks, it has additional safety implications in terms of complex machinery and the use of weapons [7]. Furthermore, the inability of military personnel to engage in activities of daily living such as work when deployed can place a strain on the combat effectiveness of military units [8]. 


\section{Original Research}

Identification of those service personnel at increased risk of dental morbidity is therefore essential in order to address their disease and instigate preventative regimes. Service Personnel are subject to periodical dental inspection in order to report on the dental health of the Armed Forces, to quantify dental risk and apportion dental resources appropriately. Dental fitness is categorised with the aim being to assess if any preventative advice or operative dental treatment is required in order that the patient is taken to a level of dental fitness in which they are unlikely to present with a dental emergency within their dental recall period. Although dental examinations should normally be undertaken prior to deployment, the risk of dental pathology and trauma cannot be fully eliminated with the incidence of dental emergencies in a 'well-prepared' force being relatively low (15-20\%) when compared to an 'ill-prepared' force (75\%) [9]. Service personnel categorized as increased risk during their dental assessment experience significantly higher rates of dental morbidity when deployed abroad [10-14].

The initial dental inspection (IDI) is undertaken when a UK military recruit joins the Service with Army recruits known to have higher incidences of dental diseases than their civilian counterparts [15]. A resultant emphasis on treating dental disease in initial training occurs within the UK Armed Forces prior to recruits being transferred to their respective single Services and therefore liable for deployment.

A literature review did not demonstrate any investigation into the Oral Health Related Quality of Life of military recruits. A cross-sectional study of Australian Army Recruits found DMFT rates of 3.59-4.63 in 17-25-year-olds, and caries present in 1.43-1.69 teeth. Socioeconomic status was also considered, and found almost double the DMFT in labourers (SES 5) compared to professionals (SES 1) [16]. A study by Skec et al [17] found caries levels of 5.8 teeth in recruits, compared to 2.7 teeth in professional (trained) soldiers. A further study by Skec [18] looked at combat readiness of the Croatian Army, looked at similar parameters to our paper, including the presence of abscesses, pain, caries and fistula's. Unfortunately, these data were not presented split between recruits and professional soldiers.

The aim of this study was to determine the incidence of dental extractions and the dental health of a sample of new infantry recruits, to ascertain how the presence of oral disease 


\section{Original Research}

will impact OHRQoL. Caries and PUFA prevalence could additionally be related to tooth extraction incidence and compared to recruits from the general military population.

\section{Method}

\section{Measures}

Dental caries and failures of restorations are associated with over two thirds of all UK dental emergencies when deployed [14]. An additional method of risk stratification is using the PUFA criteria, and was measured in the latest (2009) decennial Adult Dental Health Survey (ADHS) [19]. PUFA comprises four parameters: presence of severely decayed teeth with teeth with visible pulp involvement $(\mathrm{P})$, ulceration caused by dislocated tooth fragments $(U)$, presence of a fistula (sinus) (F) and the presence of an abscess (A) [20]. These are important factors as they represent conditions that require urgent care and are likely to have a negative impact on an individual's functioning including sleep and concentration.

\section{Setting}

Our study was performed at the British Army's Infantry Training Centre (ITC) Catterick, responsible for training of all new UK infantry recruits. Approximately 3000 recruits are present at any moment and is served by a Defence Primary Healthcare (DPHC) Dental Centre. This sample of recruits was selected due to the known burden of dental disease [15] and that infantry are usually in roles which require them to be located in isolated patrol bases and therefore the impact of a dental emergency on operations can have significant consequences. In January 2009, the Defence Dental Services established a primary care based oral surgery referral service in North Yorkshire (Catterick Garrison) to improve access to specialist Oral Surgery services [21]. A factor in selecting the Catterick location was due to the proximity of the British Army Infantry Training Centre (ITC). This strategic placement of a specialist oral surgeon afforded ITC general dental practitioners an ease of access to specialist support should an exodontia procedure be deemed or become challenging. Furthermore, the ITC exodontia burden allowed foundation dentists and dentists preparing for deployment/employment in remote locations to further develop their skills in oral surgery. 


\section{Original Research}

A retrospective data analysis of recruit integrated electronic Integrated Healthcare Records (elHR) between 01 Jan and 31 Dec 2018 was used to determine the incidence of dental extractions conducted at ITC Catterick and compared to that across the entire UK military recruit population. Secondly, a cross-sectional study was performed at ITC Catterick. Following a pilot study, a questionnaire was issued to all 211 new recruits comprising a single term, immediately prior to undergoing their initial dental inspection (Figure 1). All recruits attending for their Initial Dental Inspection (IDI) were selected to avoid selection bias. This was completed in the waiting room following a briefing from a member of the research team and a chance to read the participant information sheet, after which informed consent was obtained. No identifiable information was collected. This questionnaire explored key domains from the ADHS 2009 and Oral Health Impact Programme 14 (OHIP-14) which would have a significant impact in relation to Military service. Following additional training in the PUFA index, two military dentists experienced in performing IDIs independently collected PUFA data in addition to a comprehensive oral assessment. Data were cleaned and pseudonymised before being analysed using IBM SPSS ${ }^{\circledR}$ by a researcher not involved in the IDI process. The prevalence of existing caries was ascertained, as well as the risk of developing dental disease in the future, using the PUFA criteria.

\section{Questionnaire}

We are aware that OHIP-14 is validated for specific conditions e.g. irreversible pulpitis, pericoronitis [5] whilst EQ-5D-5L may have been an option to calculate a score for QoL. We based data collection on the ADHS 2009 framework, specifically theme 3 with OHIP-14 and EQ-5D-5L not validated against the PUFA index. Although it may have been of interest and more scientifically robust to use one of these tools, it is not unusual for investigators investigating OHRQoL to ask additional questions to explore specific impacts relating to the aims of their study [22]. We felt that of particular importance for the military cohort was loss of sleep, time off work, inability to complete jobs and feeling self-conscious. There is clear overlap with both the ADHS 2009 and the OHIP-14 in these questions. We have been able to analyse responses to these key questions against disease levels and this offers more useful data in our Military population than a score exploring overall impact on OHRQoL.

\section{Sample size}




\section{Original Research}

Sample size calculations were not undertaken. All recruits from an intake were targeted to provide a representative sample.

\section{Results}

\section{Tooth Extraction Incidence}

Analysis of elHR for all recruit training centres over a single 12-month period demonstrated that at ITC, a cohort of 547 recruits required 91 extractions at a rate of 166.4 extractions per 1,000 recruits per year. This rate was over 2.4 times higher than that observed across all UK AF trainees (Table 1) and a greater proportion of the inspected ITC recruit cohort (51/547, 9.3\%) versus all UK AF recruits $(417 / 8,637,4.8 \%)$ required at least one tooth extraction. The mean number of extractions required per recruit was also higher in ITC recruits, but a greater proportion of ITC recruits left training having had their oral surgery treatment needs met than across all training locations as a whole.

\section{Questionnaires}

Correctly completed questionnaires were received from all 211 persons (100\% response rate) invited to participant. The median age of recruits sampled was 21 years (range 18-32 years), and all were male.

\section{Overall prevalence of caries and PUFA lesions in this cohort}

$135 / 211(64 \%)$ recruits were found to have caries present at initial inspection and $37 / 211$ (18\%) had a PUFA lesion. The most prevalent PUFA lesion was an open pulp (Table 2), followed by an abscess. Seven recruits had more than one PUFA lesion

\section{Dental attendance related to PUFA lesions and caries}

$46 / 211$ (22\%) recruits reported attending the dentist for 'regular' check-ups, with a further $66 / 211$ (31.3\%) attending 'occasionally'. Those reporting that they only attended for pain, 


\section{Original Research}

experienced the highest overall proportion of PUFA and caries lesions. PUFA lesions were significantly more common in individuals who only attended the dentist in the event of pain in the past five years, versus regular, occasional or never attenders (OR 4.25, 95\%Cl: $1.96-$ 9.19, $p=0.0001)$.

\section{Self-reporting of pain and dental health}

$40.3 \%$ of recruits reported having dental pain in the last 12 months, with $4.7 \%$ actually in pain at the time of their Initial Dental Examination. Those recruits who reported pain were far more likely to have a PUFA lesion present than those without pain (70.1\% versus $14.4 \%$ ). Although recruits with poorer dental health recognised they were more likely to require treatment, the correlation was poor. Recruits that felt they needed dental treatment had a PUFA lesion present in $33.3 \%$ and caries in $76.9 \%$ of individuals. However, recruits responding that they did not need treatment still had a PUFA lesion present in $7.8 \%$ and caries in $54.3 \%$.

\section{Impact of PUFA on Oral Health Related Quality of Life}

86/211 (41\%) recruits experienced dental pain in the previous 12 months, with 10/211 (5\%) in pain at the time of their IDI. Those recruits who reported pain in the past 12 months were significantly over twice as likely to have a PUFA lesion (Figure 2) present than those without pain (OR $2.7,95 \% \mathrm{Cl}: 1.29-5.65, \mathrm{P}=0.00083)$. Significantly more recruits who rated their oral health as 'bad' had a PUFA lesion at the time of examination than those rating it as very good, good or fair (OR 2.80, 95\% Cl: 1.22, 6.42, $\mathrm{p}=0.015$ ).

67/211 (32\%) recruits reported feeling self-conscious about their teeth over the previous 12 months. 31/211 (15\%) recruits reported losing sleep in the last 12 months due to dental pain (Figure 3). Significantly more individuals reported disturbed sleep had a PUFA lesion on examination than those that did not (OR 5.62, 95\% Cl: 2.44-12.91, $\mathrm{p}<0.0001$ ).

20/211 (10\%) reported having difficulty completing daily tasks, and 17/211 (8\%) had been forced to take time away from work due to dental pain. Significantly more individuals 


\section{Original Research}

reported difficulty in completing daily tasks who had a PUFA lesion on examination than those that did not (OR 3.72, 95\%Cl: 1.40-9.90, p=0.0084). 16/211 (8\%) had been absent from work in the last 12-months due to dental pain. There was no significant difference in the odds of an individuals reporting absence from work with a PUFA lesion compared to those that did not (OR $1.6495 \% \mathrm{Cl}: 0.50-5.40, \mathrm{p}=0.418$ ). 


\section{Original Research}

\section{Discussion}

The aim of this study was to determine the incidence of dental extractions and the dental health of a representative sample of new infantry recruits and determine the impact of dental health on OHRQoL. The overall burden of dental disease in these new recruits was high, with $64 \%$ having caries at the time of inspection. This is substantially higher than found in the general population, as evidenced by a prevalence of $30 \%$ found in a similar age group in the 2009 ADHS. [19] In addition 18\% of recruits had a 'PUFA' lesion, compared to $7 \%$ in the general population [19]. The rate of extractions required in an infantry recruit cohort was 2.4 times higher than that observed across all UK AF trainees.

Such a high level of disease at an early stage in a career necessitates significant resources to counter it. This analysis has demonstrated that these high levels of caries and PUFA lesions correlates with the high numbers of extractions required at ITC Catterick as identified in previous analyses $[15,21]$. A failure to address these lesions may have adverse consequences at a later date, particularly when on deployment overseas. Only $21.8 \%$ of recruits reported attending for regular check-ups compared to $61 \%$ in the general population [19]. Regular dental inspections that are compulsory in the military enable this imbalance to be addressed [23], that would have continued had they not joined the Army.

Poor oral health and dental pain is known to have a negative impact on OHRQoL $[18,19]$. This study has demonstrated that the biggest impact of poor oral health on Army recruits was on sleep and its subsequent result on work performance. 15\% of Army recruits stated that they had lost sleep in the last 12 months due to dental pain, $10 \%$ of recruits said that pain had made it difficult to perform their daily job and $8 \%$ had been forced to go off sick from work with dental pain. Pain and sleep loss have adverse effects on concentration, which is most marked on exercise and operations. This could be considered dangerous in many circumstances in the military, due to requirements of decision making under pressure and the use of potentially dangerous equipment including weaponry.

The correlation between self-reported oral health and PUFA lesion presence is important, and corresponds to that found in a study of U.S. Army recruits [24]. However, in contrast to 


\section{Original Research}

that study, UK Army recruits had a poor understanding that this corresponded to a need for treatment, with over half of recruits with caries believing that they didn't need treatment. This may explain the low rates of attendance for checkups prior to enlisting despite the high prevalence of caries. Those with PUFA lesions were more likely to recognise that their poor oral health required treatment, and also more likely to seek dental care due to pain, reflecting that the criteria for PUFA are conditions more likely to be symptomatic than caries alone. It is also therefore worth highlighting that soldiers with significant dental disease, defined by the presence of a PUFA lesion, are more likely to require emergency dental care due to pain.

The PUFA lesions in the ITC recruit cohort were associated with a negative impact on OHRQoL, particularly sleep loss, and required operative management such as extraction. A higher proportion of recruits at ITC required an extraction than at other training locations and the higher extraction rate reflects this increased need. Evidence from the current UDA contract suggests that exodontia cases are increasingly being referred rather than treated in primary care [25]. The findings of this study may be of interest to commissioners of Intermediate minor oral surgery (IMOS) services as proposed by NHS England [26] as these services may be able to offer treatment earlier to reduce the impacts of PUFA lesions on OHRQoL.

The authors recognise potential limitations to this analysis, in particular in making direct comparisons with the population described by the Adult Dental Health Survey [19]. For example, British Army recruits remain predominantly under 25 years old, caucasian and are more likely to be from more deprived socio-economic backgrounds [15]. That being said, this highlights the unique clinical challenge this cohort represents. Although the sample was presentative of an ITC recruit intake, it may have lacked the power to identify the full impact of OHRQoL. For example, the lack of statistical significance between individuals absent from work with a PUFA lesion may have been due to the small sample. In addition, there are limitations in the ability of cross-sectional design/odds ratios to determine causality and the sample only looking at infantry recruits. 


\section{Original Research}

\section{Conclusions}

Those military recruits with caries and PUFA lesions had worse OHRQoL than those that did not. This was evidenced by poorer sleeping patterns and an inability to perform tasks at work. The poor correlation between perceived and actual dental health in our population supports current UK Military guidelines for dental inspection frequency based upon risk. Treatment of dental disease through extractions was higher in Army recruits and will likely reduce the number of days taken off sick, but its effect on overall OHRQoL cannot yet be substantiated. This study helps support a need to compare the results to other training centres in the UK, particularly those of the Navy and Royal Air Force so that the provision of future dental services can be accurately planned.

\section{Disclosure Statement}

The authors declare no conflict of interest. 


\section{Original Research}

\section{References}

1 Combes J, Pepper T, Bryce G and MacBeth N. Dental care provision to UK military personnel serving on Operation Herrick in Afghanistan. Part 1: Access to dental care. British Dental Journal 2018; 225: 1068-1072

2 Gunepin M, Derache F, Blatteau JE, Bombert C, Simecek J. Medical evacuation of French Forces for Dental Emergencies: Operation Serval. Military Medicine 2015; 180 : 578-581

3 Mitchener TA, Hauret KG, Hoedebecke EL, Darakjy S, Jones BH. Air medical evacuations of soldiers due to oral-facial disease and injuries, Operations Enduring Freedom/Iraqi Freedom. Military Medicine 2008; 173: 465-473

4 Colthirst PM, Berg RG, DeNicolo P, Simecek JW. Operational cost analysis of dental emergencies for deployed US Army personnel during operation Iraqi freedom. Military Medicine 2013; 178: 427-431

5 Cimilli, H., Karacayli, U., Sisman, N., Kartal, N., Mumcu, G. Comparison of the oral health-related quality of life and dental pain in symptomatic irreversible pulpitis and pericoronitis. Journal of Dental Sciences 2012; 7(3): 250-260

6 Svensson, L., Hakeberg, M., Wide, U. Dental pain and oral health-related quality of life in individuals with severe dental anxiety. Acta Odontologica Scandinavica 2018; 21: 1-6

7 Miller, N.L., P. Matsangas, L.G Shattuck, "Fatigue and its Effect on Performance in Military environments, Performance under Stress 2007; 231-249.

8 Davies TJ, McCormick RJ. The importance of, and the benefits derived from, forward dental peripatetic clinics in Afghanistan. British Dental Journal 2015; 218: 303-306.

9 Mahoney GD, Coombs M: A literature review of dental casualty rates. Mil Med 2000; 165: 751-6.

10 Richardson, P. S. Dental Morbidity in United Kingdom Armed Forces, Iraq, 2005. Military Medicine 2005. 170: 536-541

11 Tweles, R. B., King J. E. Impact of Troop Dental Health on Combat Readiness. Military Medicine 1987; 152(5): 233-235

12 Chaffin, J., King, J. E., Fretwell, L. D. U.S. Army Dental Emergency Rates in Bosnia. Military Medicine 2001; 166(12): 1074-1078

13 York, A. K., Moss, D. L., Martin, G. A Longitudinal Study of Dental Experience during the First Four Years of Military service. Military Medicine 2008; 173(1): 38-41 
14 Dermont, M., Elmer, T. B., McCormick, R. A bridge too far? The relationship between interventive operative dentistry and future dental morbidity. Br Dent J online 2019; 226(7): 498

15 Elmer, T B, Langford J, McCormick R, Morris AJ. Is there a differential in the dental health of new recruits to the British Armed Forces? A pilot study. Br Dent J, 2011 211(9) 424-5

16 Hopcraft M., Morgan, M. Dental caries experience in a young adult military population. Australian Dental Journal 2003; 48(2): 125-129

17 Skec, V., Macan, J. S., Susac, M., Jokic, D., Brajdic, D., Macan, D. Influence of Oral Hygiene on Oral Health of Recruits and Professionals in the Croatian Army. Military Medicine 2006; 171(10): 1006-1009

18 Skec, V., Macan, D., Spicek, J., Susac, M., Luksic, I. Influence of Oral Health on Combat Readiness in the Croatian Army. Military Medicine 2002; 167(12): 10161019

19 Adult Dental Health Survey 2009 - Summary report and thematic series. Accessed 20 June 2019. https://digital.nhs.uk/data-andinformation/publications/statistical/adult-dental-health-survey/adult-dental-healthsurvey-2009-summary-report-and-thematic-series

20 Monse, B., Heinrich-Weltzien, R., Benzian, H., Holmgren, C., Van Palenstein Helderman, W. PUFA- An index of clinical concequences of untreated dental caries. Community Dentistry and Oral Epidemiology, 2010; 38(1): 77-82

21 Davies B, Ramsey R, Bryant D, Mackenzie N. A service review of a novel primary care specialist oral surgery referral service operating in a managed clinical network. Oral Surgery 2013; 6(2): 61-66

22 Currie CC, Stone SJ, Durham J. Pain and problems: a prospective cross-sectional study of the impact of dental emergencies. Oral Rehab 2015; 42: 883-889.

23 Nice 2004. Clinical Guideline CG19. Dental checks: intervals between oral health reviews. Available at: https://www.nice.org.uk/guidance/cg19 (Accessed Jun 2019)

24 Chisick, M. C., Poindexter, F. R., York, A. K. Factors influencing perceived need for dental care by United States military recruits. Military Medicine 1997; 162(9): 586589

25 Davies B J, Macfarlane F. Clinical decision making by dentists working in the NHS General Dental Services since April 2006. Br Dent J 2010; 209: E17.

26 NHS England. Guide for Commissioning Specialist Dentistry Services. 2015. Available at https://www.england.nhs.uk/commissioning/wp- 
content/uploads/sites/12/2015/09/introguidecommsdentspecl.pdf (Accessed Sept 2020).

Table 1. Summary of extractions indicated and undertaken at ITC and all recruit training locations.

\begin{tabular}{|l|l|c|l|l|}
\hline & $\begin{array}{l}\text { Rate of } \\
\text { extractions } \\
\text { required / } \\
1,000 \\
\text { recruits/year }\end{array}$ & $\begin{array}{l}\text { Mean number of } \\
\text { extractions } \\
\text { required/recruit }\end{array}$ & $\begin{array}{l}\text { Completed } \\
\text { extraction rate } \\
\text { per 1,000 } \\
\text { recruits per } \\
\text { year }\end{array}$ & $\begin{array}{l}\text { Proportion of recruits } \\
\text { requiring extraction } \\
\text { whose treatment was } \\
\text { completed during } \\
\text { training }\end{array}$ \\
\hline ITC Recruits & 166.4 & 1.8 & 75.0 & $62.7 \%$ \\
\hline $\begin{array}{l}\text { All UK AF } \\
\text { Recruits }\end{array}$ & 68.9 & 1.4 & 28.7 & $59.5 \%$ \\
\hline
\end{tabular}

Table 2: Prevalence of PUFA lesions found in the 211 recruits examined and surveyed.

\begin{tabular}{|l|l|}
\hline Lesion & Incidence $(\mathbf{n}=\mathbf{2 1 1})$ \\
\hline Open Pulp & $33(15.6 \%)$ \\
\hline Abscess & $5(2.4 \%)$ \\
\hline Ulceration & $4(1.9 \%)$ \\
\hline Sinus & $2(0.9 \%)$ \\
\hline None & $174(82.5 \%)$ \\
\hline
\end{tabular}

Figure 1: Questionnaire

Figure 2: The association between PUFA lesion presence at inspection and past pain

Figure 3: The association between PUFA lesions and loss of sleep 